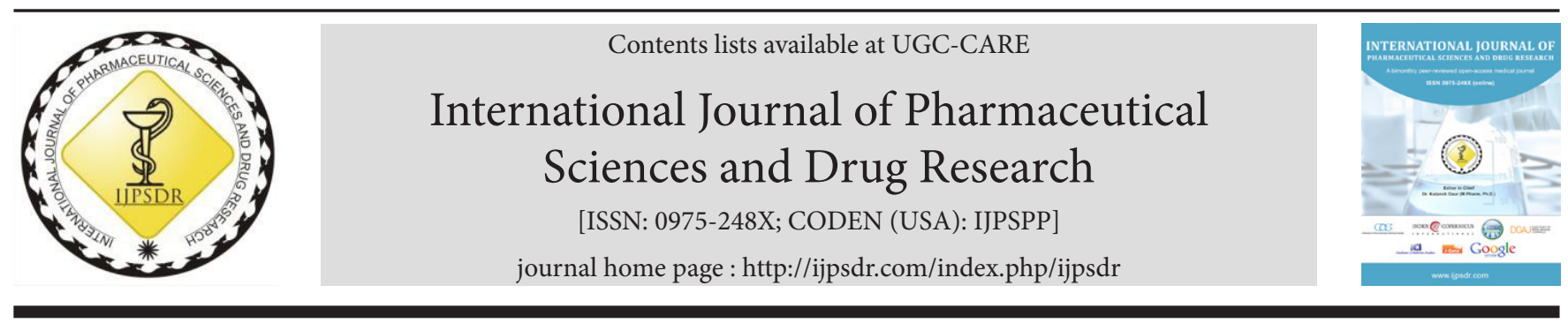

Research Article

\title{
Bioactivity and Apoptotic Efficacy of the Purified Terpenoid Extract from the Moss Brachythecium buchananii (Hook.) A. Jaeger against MG-63 Cells
}

\author{
Geetha Mohandas Greeshma ${ }^{1}$, Gopal Sarayu Manoj ${ }^{1}$, Kumaraswamy Murugan ${ }^{2 *}$ \\ ${ }^{1}$ Department of Botany, Mahatma Gandhi College, Thiruvananthapuram, Kerala, India \\ ${ }^{2}$ Government Arts College, Thiruvananthapuram, Kerala, India
}

\begin{tabular}{l} 
A R T I C L E I N F O \\
\hline Article history: \\
Received: 25 March, 2020 \\
Revised: 29 April, 2020 \\
Accepted: 05 May, 2020 \\
Published: 30 May, 2020 \\
Keywords: \\
Anticancer, Apoptosis, \\
Caspase, \\
DNA fragmentation, \\
Moss, Terpenoid. \\
D0I: \\
10.25004/IJPSDR.2020.120312
\end{tabular}

\section{INTRODUCTION}

Bryophytes are the oldest amphibian plants that differ from all other lignified vascular plants in terms of their dominant gametophytic generation with dependent sporophyte. Bryophytes generally fall into three lineages, such as liverworts (Marchantiophyta), hornworts (Anthocerotophyta), and mosses (Bryophyta). ${ }^{[1]}$ These plants are generally dominated in dampy microenvironment and cool temperate forests. But, some are aquatic, and others require a humid condition. Some bryophytes possess remarkable resurrection power and can survive extended periods of desiccation and, when rewetted, revive to resume normal growth. Bryophytes are good indicators of air and water pollution. Mosses are considered to be the closest sister to the vascular plants and have significant ethnic and ecological values. For example, peat moss Sphagnum is one of the most economically important bryophytes. Because of their special epidermal cells, Sphagnum species are frequently added to potting soil to increase its water-holding capacity. During World War I, Sphagnum was used on a large scale as a wound dressing material because of its acidic sterile thallus, which acts as antiseptic and also an adsorbent. ${ }^{[2]}$ Generally, bryophytes are ignored because of their small stature and lack of proven economic outputs. But, for the last few years, studies revealed that these plants are exceptionally rich in medicinally valuable compounds, such as, alkaloids, phenolic acids, flavonoids, terpenoids, tannins, saponins,

\footnotetext{
*Corresponding Author: Dr. Kumaraswamy Murugan

Address: Government Arts College, Thiruvananthapuram, Kerala, India

Email $\square$ : harimurukan@gmail.com

Relevant conflicts of interest/financial disclosures: The authors declare that the research was conducted in the absence of any commercial or financial relationships that could be construed as a potential conflict of interest.

Copyright (C) 2020 Geetha Mohandas Greeshma et al. This is an open access article distributed under the terms of the Creative Commons AttributionNonCommercial-ShareAlike 4.0 International License which allows others to remix, tweak, and build upon the work non-commercially, as long as the author is credited and the new creations are licensed under the identical terms.
} 
and phlobatannins. ${ }^{[1]}$ The present study is undertaken to analyze the antimetastatic capability of the purified terpenoids isolated from the moss $B$. buchananii.

\section{MATERIALS AND METHODS}

B. buchananii, belongs to Brachytheciaceae of Musci. The identity of the plant was confirmed by floras and authenticated by comparing it with the herbarium of the University of Calicut.

\section{Estimation of Terpenoids}

Total terpenoids were quantified by the method of Indumathi. ${ }^{[3]}$

\section{Purification and Fractionation by Gas Chromatography-Mass Spectrometry (GC-MS) Analysis}

Terpenoid from B. buchananii was extracted using methanol and was purified by silica gel column chromatography (CC). Elution was done using petroleum ether:ethyl acetate as solvent combinations from $100 \%$ petroleum ether (PE) to $100 \%$ ethyl acetate (EA) and also PE:EA combinations. Further, the purified fraction was subjected to thin layer chromatography (TLC) with the mobile phase of toluene:ethyl acetate (6:1) as combinations and subsequently analyzed by gas chromatography-mass spectrometry (GCMS). The mass spectrum of the unknown components derived from GC-MS chromatogram was compared with the mass spectral survey data of NIST library (NIST 2005), EIMS data reported in the literature were also compared with the experimental mass spectra of the moss. The order of elution of compounds was confirmed through reported retention indices (RI) data. Area normalization method was used to quantify the constituents.

\section{Anticancer Assay}

\section{Cells and Culture Conditions}

HeLa (cervical carcinoma), MDA-MB-231 (human breast adenocarcinoma), and MG-63 (human osteosarcoma) cells were procured from the National Centre for Cell Sciences (NCCS), Pune, India and maintained on Dulbecco's modified Eagle's medium, DMEM (Sigma Aldrich, USA), as per the manufacturer's instruction.

\section{Cytotoxicity and Apoptosis Assay}

Cell viability was assessed by MTT reduction assay. ${ }^{[4]}$ The three cell lines were cultured as per the standard procedure and analyzed the $\mathrm{IC}_{50}$ concentration. The cell cycle and apoptosis were analyzed by flow cytometer.

\section{DNA Fragmentation Analysis}

The DNA fragmentation was analyzed in the MG-63 cells treated with different doses $(0,25,50$, and $100 \mu \mathrm{g} / \mathrm{mL})$ of purified terpenoid extracts. Both the attached and floating cells were harvested and washed with phosphate buffered saline (PBS) buffer. Subsequently, the pellets were lysed with DNA lysis buffer [ $20 \mathrm{mM}$ ethylenediamine tetraacetic acid (EDTA), $100 \mathrm{mM}$ Tris, pH 8.0, 0.8\% sodium dodecyl sulphate (SDS)] at room temperature for 20 minutes. Further, the cells were centrifuged for 10 minutes at $12,000 \mathrm{rpm}$, and the supernatants were treated with RNase A (final dose of $500 \mu \mathrm{g} / \mathrm{mL}$ ) for 20 minutes at $37^{\circ} \mathrm{C}$, followed by proteinase $\mathrm{K}$ digestion with (final concentration $500 \mu \mathrm{g} / \mathrm{mL}$ ) for 3 hours at $50^{\circ} \mathrm{C}$. The total DNA was extracted using the 25:24:1 phenol/chloroform/ isoamyl alcohol, precipitated with ethanol, dissolved in 10 mM Tris, pH 8.0, 1 mM Tris-EDTA (TE) buffer and subjected to $2 \%$ agarose gel electrophoresis for DNA fragmentation assay.

\section{Migration and Invasion}

To analyze the cell migration, wound healing assay was performed. ${ }^{[5]}$ Cell invasion was carried by the invasion of the MG-63 cells through 24-well matrigel-coated transwell inserts. Transwell inserts with an $8 \mu \mathrm{m}$ pore size were coated with $100 \mu \mathrm{L}$ of a $1 \mathrm{mg} / \mathrm{mL}$ Matrigel in cold serum-free medium. The lower chamber was filled with a medium containing fetal bovine serum as chemoattractant. The coated filter and upper chamber were laid over the lower chamber. MG-63 cells were pre-incubated with different concentrations $(25,50$, and $100 \mu \mathrm{g} / \mathrm{mL}$ ) of terpenoid extracts for 48 hours duration at room temperature and then, cell suspension treated with terpenoid extract was seeded on to the upper chamber walls. After incubation for 20 hours at $37^{\circ} \mathrm{C}$, the filter was fixed and stained with $25 \mathrm{~mL}$ ethanol containing $0.2 \%$ crystal violet for 15 minutes. After being dried, the stained cells were enumerated and photographed. For quantification, the invaded stained cells on the other side of the membranes were extracted with $31 \%$ acetic acid and read colorimetrically at $590 \mathrm{~nm}$ (Zheng et al., 2011).

\section{Western Blotting Assay ${ }^{[6]}$}

Western blot technique was employed to evaluate the anti-apoptotic (Bcl-2, pro-caspase 3) and apoptotic protein (Bax) expression following treatment with purified terpenoid extracts $(0,6.25,12.5,25,50$, and 100 $\mu \mathrm{g} / \mathrm{mL}$ ) on MG-63 cells.

\section{Lactate Dehydrogenase Assay}

Membrane integrity was assessed by estimating the amount of lactate dehydrogenase (LDH) present in the culture media. The cytosolic enzyme LDH will be released due to membrane damage. ${ }^{[7]}$

\section{Signaling Pathways}

Mitogen-activated protein kinase signaling pathway, ${ }^{[8]}$ caspase cascade, ${ }^{[9]}$ and antioxidant enzyme pathways ${ }^{[10]}$ were also analyzed.

\section{Statistical Analysis}

The data was the mean of three replicates. Statistical significance was analyzed using a student's t test 
(two-tailed). p $<0.05$ was considered as statistically significant difference.

\section{RESULTS AND DiscuSSION}

The optimal level of total terpenoid content from the crude methanolic extract of $B$. buchananii was noticed, i.e., $4.3 \mathrm{mg} / \mathrm{g}$. Subsequently, the crude terpenoid content was purified using silica gel G column chromatography and was eluted with different combinations of petroleum ether:ethyl acetate. Interestingly, 100\% PE, 95:5 (PE:EA), and 90:10 (PE:EA) showed promising results. The three eluted combinations were further subjected to TLC. The 100\% PE eluted fraction of B. buchananii showed a single band on TLC, and in GC-MS analysis showed the presence of hexadecane, hexadecanoic acid, octadecane, heneicosane, and tetracosane. The analysis of the 95:5 fraction showed six bands on TLC with the presence of dodecanal, octadecane, dodecane, hexadecane, nonadecane, heptadecane, stigmasterol (triterpenoid), and heneicosane on GC-MS analysis. The 90:10 (PE:EA) eluted fraction also showed six bands on TLC. The band was fractionated using GC-MS showed the presence of dodecanal, hexadecane, tetradecanal, 6, 10, 14-trimethyl2-pentadecanone (sesquiterpenoid), and heptadecane. All these compounds were already found to be listed in the terpenoids library list of MassFinder 4 software indicating them as terpenoids/terpenoid related compounds.

\section{Cytotoxicity (MTT assay)}

Cytotoxicity of purified terpenoid of $B$. buchananii against the HeLa, MDA-MB-231, and MG-63 osteosarcoma cell lines $(0,6.25,12.5,25,50$, and $100 \mu \mathrm{g} / \mathrm{mL})$ for different time spans $(0,24$, and 48 hours) revealed a concentration and duration-dependent impact (Table 1). The viability of the MG-63 cells treated with $100 \mu \mathrm{g} / \mathrm{mL}$ for 24 hours was remarkably reduced when compared to others, i.e., $38.48 \%$. Further, antimetastatic studies were continued only with MG-63 cells lines.

\section{Cell Morphology of MG-63 using Light Microscopy}

MG-63 cells were cultured for 24 hours with different doses of terpenoids $(0,6.25,12.5,25,50$, and $100 \mu \mathrm{g} / \mathrm{mL})$. No remarkable morphological changes were observed in the MG-63 cells treated with terpenoid at 6.25 and
$12.5 \mu \mathrm{g} / \mathrm{mL}$ for 24 hours. However, the cells exhibited sound morphological anomalies, such as, blebbing with irregular shaped cells, shrinkage, and chromatin condensation, when treated with 50 and $100 \mu \mathrm{g} / \mathrm{mL}$ terpenoid extract (Fig. 1).

\section{Inhibition of Cell Migration and Invasion by Purified Terpenoid Extract}

The inhibitory effects of terpenoid extract on the chemotactic migration of MG-63 cells was evaluated using wound-healing assay. Cells were carefully wounded and a continuous cell-free wound region was created. After 48 hours of incubation with purified terpenoid extract, the migration caliber of MG-63 cells to move into the wound region was significantly reduced in a dose-dependent manner (50 and $100 \mu \mathrm{g} / \mathrm{mL}$ ) (Fig. 2). One of the most critical events in tumor progression is

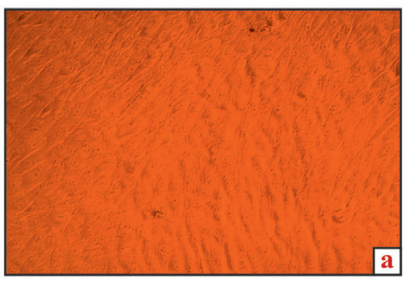

Control

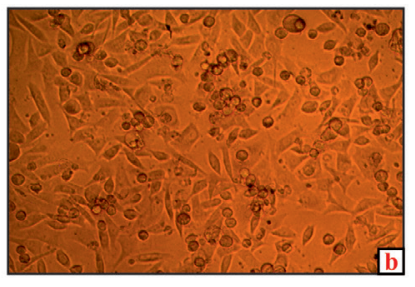

$6.25 \mu \mathrm{g} / \mathrm{ml}$

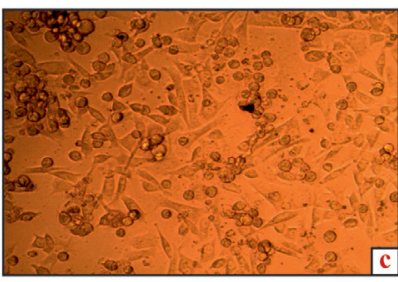

$12.5 \mu \mathrm{g} / \mathrm{ml}$

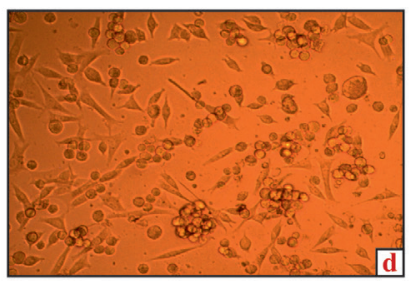

$25 \mu \mathrm{g} / \mathrm{ml}$

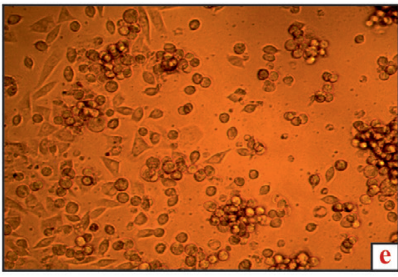

$50 \mu \mathrm{g} / \mathrm{ml}$

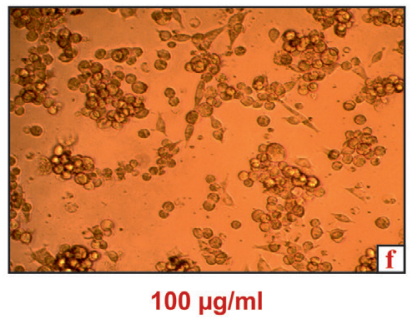

Fig. 1: The phase-contrast micrographs of MG-63 cells treated with various doses of terpenoid extract from $B$. buchananii

Table 1: Percentage of viability of HeLa, MDA-MB-231, and MG-63 cells against the purified terpenoid extract of B. buchananii

\begin{tabular}{|c|c|c|c|c|c|c|}
\hline \multirow{2}{*}{$\begin{array}{l}\text { Sample concentration } \\
(\mu \mathrm{g} / \mathrm{mL})\end{array}$} & \multicolumn{2}{|c|}{ HeLa percentage viability } & \multicolumn{2}{|c|}{ MDA-MB-231 percentage viability } & \multicolumn{2}{|c|}{$M G-63$ percentage viability } \\
\hline & $24 h$ & $48 h$ & $24 h$ & $48 h$ & $24 h$ & $48 h$ \\
\hline Control & 100 & 100 & 100 & 100 & 100 & 100 \\
\hline 6.25 & 89.26 & 80.3 & 88.59 & 84.6 & 73.37 & 70.2 \\
\hline 12.5 & 76.8 & 71.4 & 79.77 & 73.4 & 68.6 & 65.5 \\
\hline 25 & 65.2 & 60.3 & 73.15 & 70.2 & 60.2 & 58.7 \\
\hline 50 & 58.9 & 56.4 & 68.44 & 64.6 & 52.88 & 50.7 \\
\hline 100 & 55.3 & 50.71 & 65.7 & 61.4 & 38.48 & 36.37 \\
\hline
\end{tabular}


Table 2: Purified terpenoid induces apoptosis after 48 hours on MG-63 cells

\begin{tabular}{lllll}
\hline Concentration $(\mu \mathrm{g} / \mathrm{mL})$ & Live $(\%)$ & Early apoptosis (\%) & Late apoptosis (\%) & Dead (\%) \\
\hline Control & 91.86 & 5.84 & 2.48 & 0.02 \\
6.25 & 80.2 & 9.4 & 9.7 & 0.48 \\
12.5 & 71.32 & 13.8 & 14 & 0.63 \\
25 & 59.4 & 15.8 & 16 & 9.02 \\
50 & 50.17 & 21.2 & 18.02 & 10.32 \\
100 & 40.2 & 22.5 & 21.08 & 16.2 \\
\hline
\end{tabular}

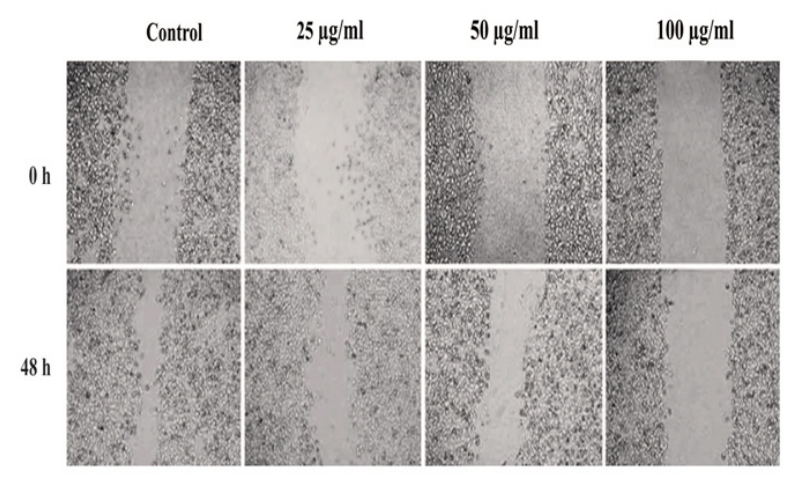

Fig. 2: Effect of terpenoid extract on the migration of MG-63 cells; model of wound-healing at 0 and 48 hours

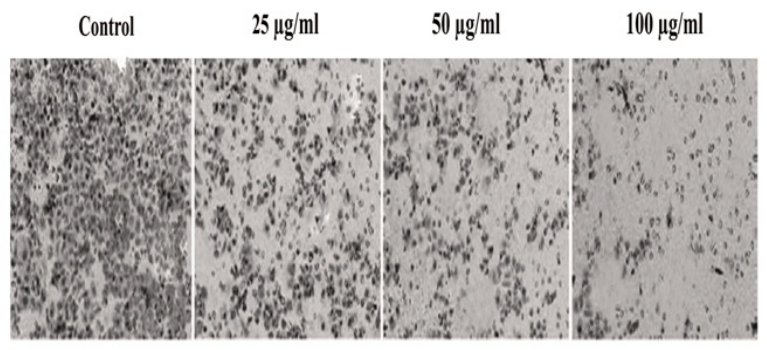

Fig. 3: Invasion inhibition of terpenoid extract on MG-63 pretreated with the indicated concentrations after 48 hours

the growth of the vascular network, such as, new blood and lymphatic vessels (angiogenesis) to supply nutrients, oxygen, and to remove waste products. To analyze the impact of terpenoids on tumor invasion and metastasis, the invasion assay was also performed, and the results were consistent with the observations obtained with the wound-healing assay (Figs 3 to 5). Terpenoids significantly inhibited MG-63 invasion in a dose-dependent manner. The values were statistically significant $(\mathrm{p}<0.05)$.

\section{Apoptosis Assay by Flow Cytometry}

Initial apoptosis is featured by the translocation of phosphatidylserine (PS) from the inner layer of the cell membrane to the outside. Apoptosis is viewed by estimating annexin V-FITC bonding to externalized phosphatidylserine. In the flow cytometry method,

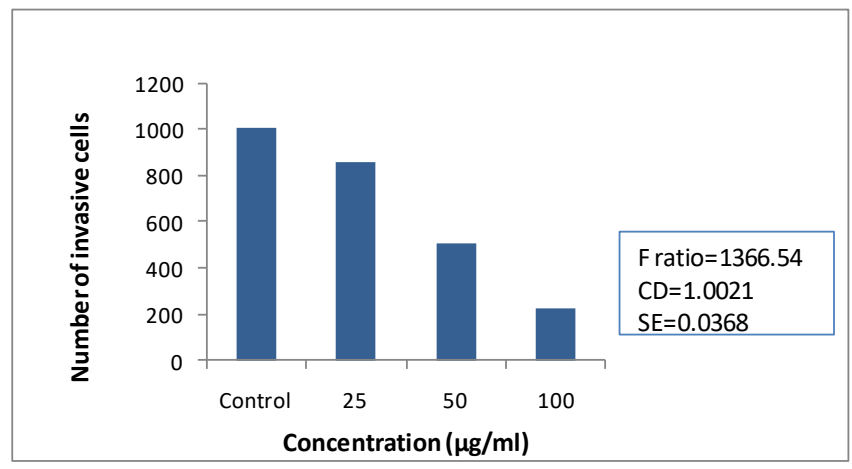

Fig. 4: Quantitative data of invasion of MG-63 cells

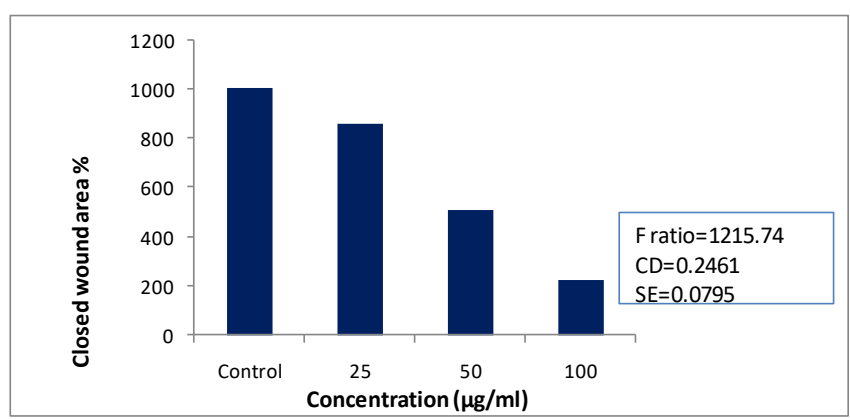

Fig. 5: Estimation of wound healing rate (\%)

annexin V/propidium iodide (ann V/PI) staining is characterized by the protein annexin $\mathrm{V}$ capacity to bond to phosphatidylserine, which is externalized on the outer plasma membrane leaflet upon apoptosis induction. In healthy cells, PS is localized in the inner membrane leaflet, but on apoptosis induction, it is translocated to the outer membrane leaflet and made available for annexin $\mathrm{V}$ binding. The flow cytometry method of MG-63 cells revealed that terpenoid extract administration leads to shifting of the cell population from viable to apoptotic events (Table 2 and Fig. 6). After treatment with $100 \mu \mathrm{g} / \mathrm{mL}$ terpenoid extract for 48 hours, the initial, late apoptotic levels and dead cells were $22.5,21.08$, and $16.2 \%$, respectively, compared with the control. Furthermore, significant change in the percentage of late-stage apoptotic cells for terpenoid extract-treated group was observed at $50 \mu \mathrm{g} / \mathrm{mL}$ terpenoid extract incubation. These results demonstrate the ability of terpenoid extract to exert significant apoptosis, particularly in early-stage apoptosis in MG-63 cells. 


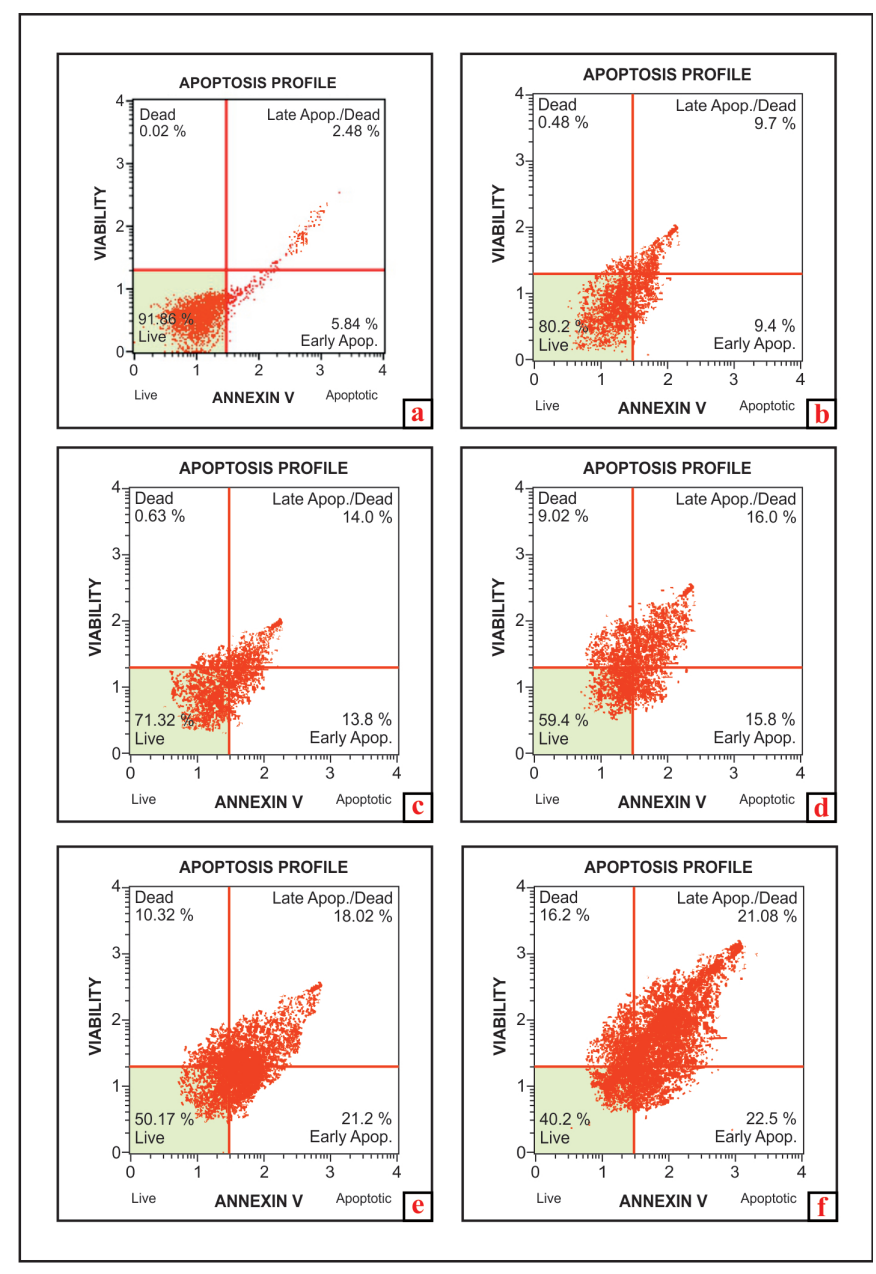

Fig. 6: Annexin V/PI double-stained assay of MG-63 cells treated with different concentrations of purified terpenoid extract for 48 hours

\section{Induction of DNA Fragmentation by Terpenoid Extract}

The DNA fragmentation was analyzed by agarose gel electrophoresis on the MG-63 cells treated with various concentrations of purified terpenoid extract (Fig. 7). In the experiments, DNA isolated from MG-63 cells treated with terpenoids for 24 hours displayed a typical ladder pattern of internucleosomal fragmentation and was comparable with cisplastin, the synthetic drug. Significant fragmentation was observed when MG-63 cells were administrated with $100 \mu \mathrm{g} / \mathrm{mL}$ of terpenoid extract. During apoptosis, DNA strand breaks and the nicks may be visualized via DNA fragmentation protocol. It is well established that apoptosis is facilitated via increased endonucleases activation, which leads to the formation of DNA fragmentation, and this can be observed through electrophoretic micrographs. Internucleosomal fragmentation of DNA, as noticed by agarose gel electrophoretic analysis, substantiates the progression of apoptosis on MG-63 cells treated with purified terpenoid extract. The results were comparable with the DNA laddering noticed with the cisplastin treated cells.

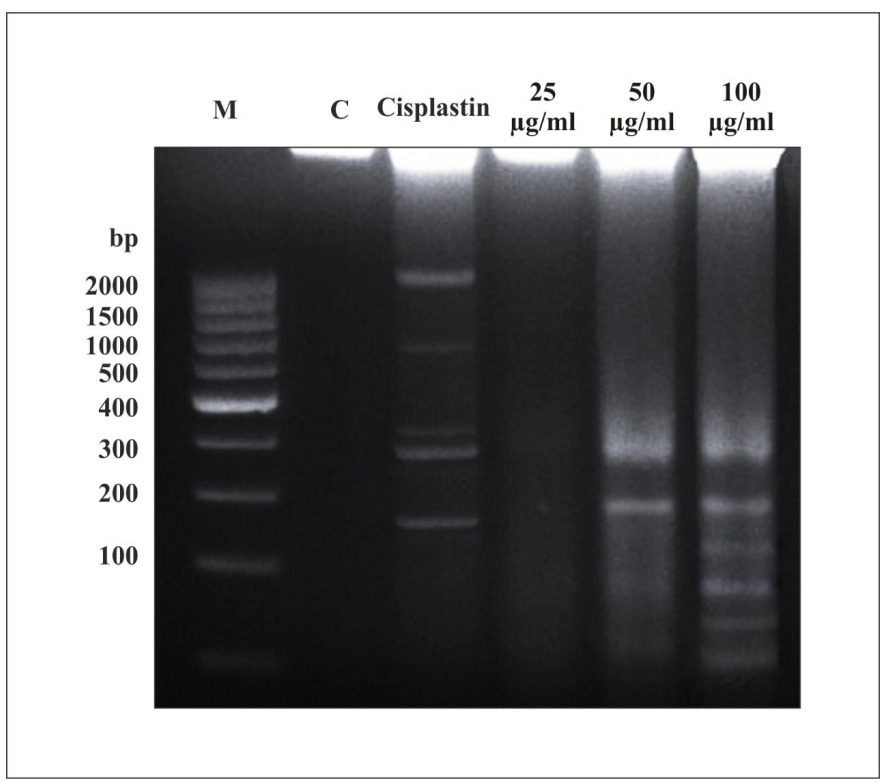

Fig. 7: DNA fragmentation on MG-63 cells treated with purified terpenoid extract from B. buchananii
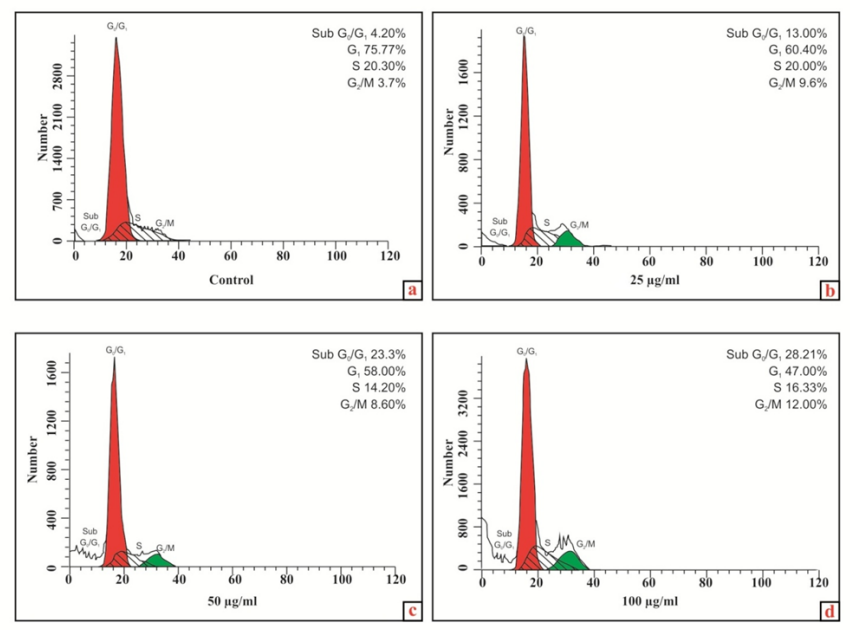

Fig. 8: Impact of purified terpenoid extract from B. buchananii on the cell cycle of the MG-63 cells

\section{Cell Cycle Analysis}

The impact of terpenoid extract on cell cycle distribution in MG-63 cells were displayed in Fig. 8. Administration of MG-63 cells with terpenoid extract resulted in remarkable enhancement of $G_{2}$ phase cells when compared to the non-treated cells. The density of cells in $\mathrm{G}_{2}$ was enhanced in a concentration-dependent manner. This enhancement was correlated with the reduced \% of cells in $S$ and $\mathrm{G}_{1}$ phases. In addition, the sub- $G_{0} / G_{1}$ cell accumulation, a biochemical indicator of apoptosis, ${ }^{[11]}$ was remarkably increased in the terpenoid extract-treated MG-63 cells than the non-treated control. The enhancement in sub- $G_{0} / G_{1}$ cells was dosedependent. Thus, the overall results suggest that terpenoid extract induced MG-63 cell death via the induction of $G_{2}$ cell cycle arrest and subsequent apoptotic events. 


\section{Western Blot Analysis}

Western blot protocol was employed for visualizing the expression level of Bcl-2 (anti-apoptotic proteins) pro-caspase 3 and the pro-apoptotic protein Bax. MG-63 cells were treated with various doses of purified terpenoids $(6.25-100 \mu \mathrm{g} / \mathrm{mL})$ and also with $100 \mu \mathrm{g} / \mathrm{mL}$ dose for different time-periods. Terpenoids down-regulated the expression of pro-caspase 3 and Bcl-2, while up-regulated Bax protein in a concentration-dependent manner (Fig. 9). Further, the duration dependent (0-48 hours) analysis of $100 \mu \mathrm{g} / \mathrm{mL}$ treated MG-63 cells revealed significant down/ upregulation of the proteins effectively from 12 hours onwards.

\section{Lactate Dehydrogenase (LDH) Assay}

The cytotoxicity of purified terpenoid extract was analyzed by LDH assay. As shown in Table 3, purified
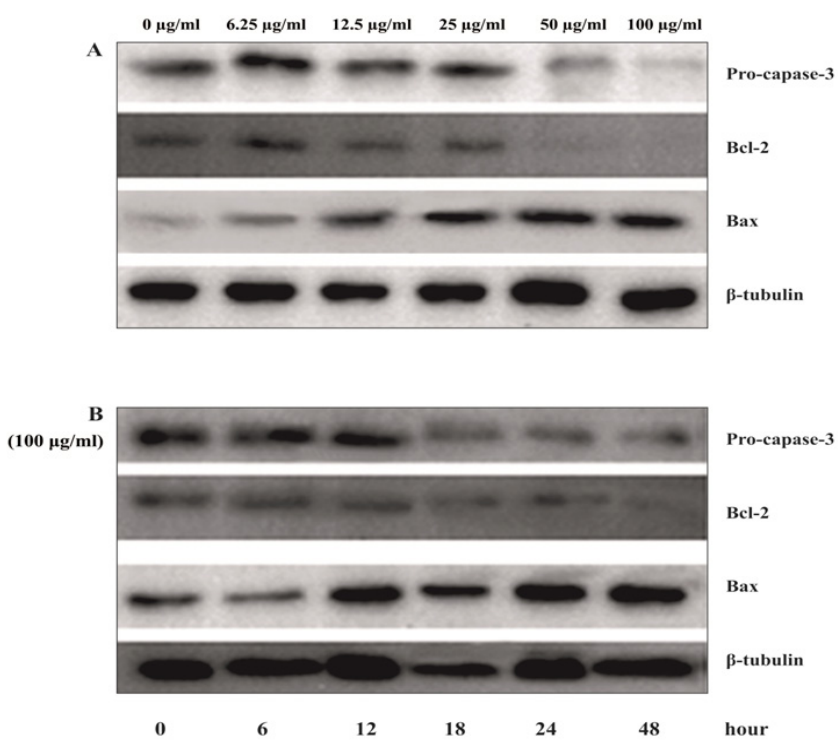

Fig. 9: Effects of terpenoid extracts on MG-63 cells in terms of anti-apoptotic protein molecules such as pro-caspase $3 \mathrm{Bcl}-2$ and apoptotic protein, such as, Bax; A: Concentration; B: Duration dependent manner $(100 \mu \mathrm{g} / \mathrm{mL})$ using Western blot analysis

Table 3: Amount of LDH released from MG-63 cells after 24 hours treatment with various doses of purified terpenoid extract from B. buchananii

\begin{tabular}{ll}
\hline Concentration $(\mu \mathrm{g} / \mathrm{mL})$ & \% of total LDH activity \\
\hline 0 & 0.007 \\
6.25 & 0.127 \\
12.5 & 2.18 \\
25 & 5.12 \\
50 & 8.95 \\
100 & 11.3 \\
F ratio & $97.73^{* *}$ \\
CD & 0.07124 \\
SE & 0.01986 \\
** - indicates $\mathrm{p}<0.01$ &
\end{tabular}

terpenoid treatment for 24 hours caused an abnormal release of LDH in a dose-dependent manner in MG-63 cells. The LDH, a stable cytoplasmic enzyme present inside the cells, is an important enzyme for energy metabolism. A large amount of LDH was released into the cell culture supernatant when the cell membrane was damaged, which can be used to evaluate the effect of a drug to cause cell death. In this work, the LDH released from the purified terpenoid extract-treated cells substantiates this.

\section{Analysis of the Signaling Pathway of Apoptosis}

Many signaling pathways are involved in regulating apoptosis events in the cells. Mitogen-activated protein kinases (MAPKs), the caspase cascade, and the antioxidant enzyme (AOX) pathway are the unique executors of apoptosis, as revealed from many anticancer ${ }^{[8,12]}$ Initially, the MAPK signaling pathway was traced using Western blot analysis to ensure the terpenoids triggered apoptosis. In fact, the cells that were pre-treated with MAPK inhibitor did not show any remarkable variations as compared with the cells treated with terpenoids only. Thus, the data reflected that terpenoids-induced apoptosis was not executed by the MAPK signaling pathway on MG-63 cell lines (Fig. 10).

Further, the role of the caspase cascade in the terpenoids $v s$. apoptosis was analyzed by MTT assay and Western blot analysis. From the expression micrographs, the caspase cascade inhibitor, Z-VAD-FMK, displayed a remarkable impact as compared with the cells treated with terpenoids only (Fig. 11). This tempts to suggest that the caspase cascade was involved in terpenoids triggered apoptosis (Table 4).

In addition, the antioxidant (AOX) enzyme pathway was analyzed to ascertain their involvement in the terpenoid triggered apoptosis. The cells that were pre-treated with

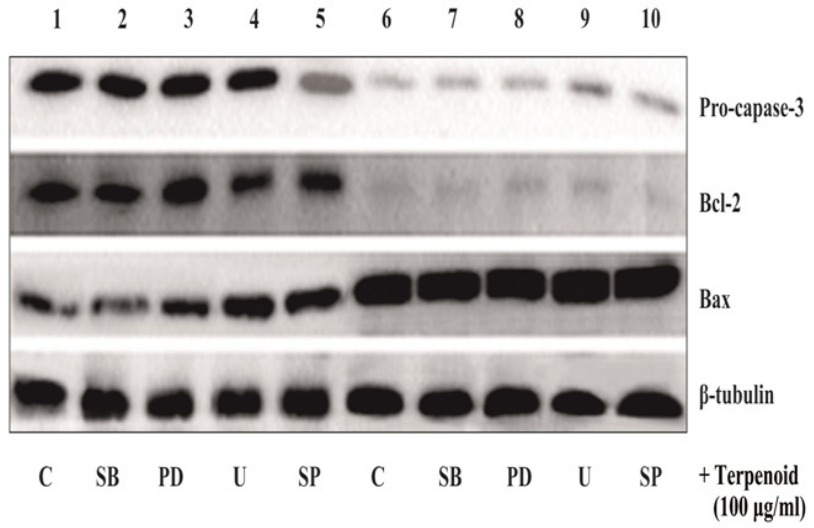

Fig. 10: Analysis of mitogen-activated kinase (MAPK) subfamilies with terpenoid treated MG-63 cells [the impact of MAPK inhibitors

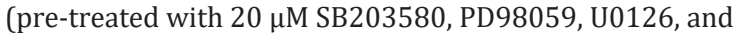
SP600125, respectively, for 60 minutes) on MG-63 cells treated with $100 \mu \mathrm{g} / \mathrm{mL}$ terpenoid for 24 hours were analyzed] 


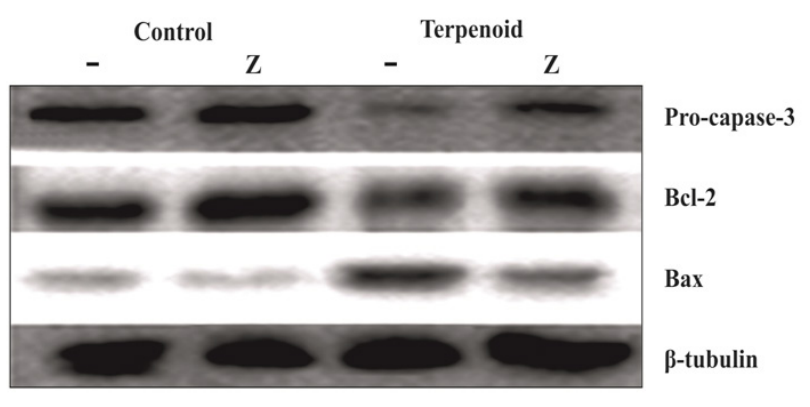

Fig. 11: Role of caspase induced apoptosis by terpenoid on MG-63 cells [influence of caspase general inhibitor (pretreatment with 20 $\mu \mathrm{M}$ Z-VAD-FMK for 60 minutes) on MG-63 cells treated with 100 $\mu \mathrm{g} / \mathrm{mL}$ terpenoids for 24 hours was analyzed using Western blot analysis]

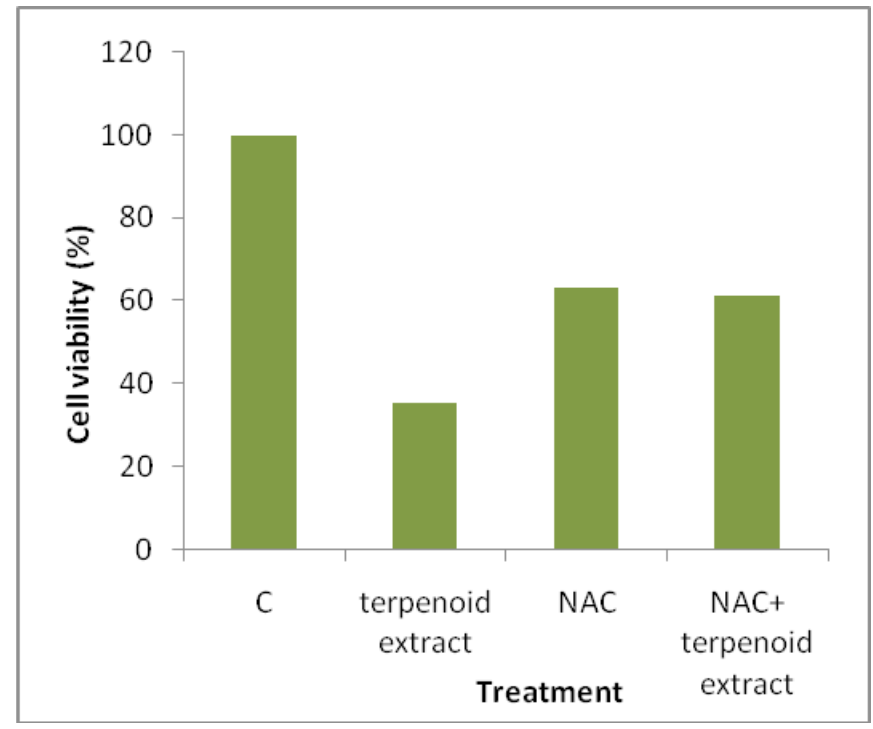

Fig. 12: Effect of N-acetyl-L-cysteine (NAC) pre-treated MG-63 cells followed by terpenoid extract $(100 \mu \mathrm{g} / \mathrm{mL})$ on cell viability

inhibitors ( $\mathrm{N}$-acetyl-L-cysteine) of antioxidant enzymes showed reduced viability of the MG-63 cells as compared with the cells treated with terpenoids only. Thus, this part of the result also suggests that antioxidant (AOX) enzyme inhibitor influenced the apoptosis via diverse strategies associated with ROS-AOX pathway (Fig. 12). Thus, it is plausible to reveal that antioxidant (AOX) enzyme machinery was involved in the terpenoids triggered apoptosis on MG-63 cells.

In this study, as an initial part of the analysis, MTT assay was carried that reflects the reduced viability of MG-63 cells treated with purified terpenoids in a dose and duration-dependent manner as compared to other cell lines. In addition, the terpenoids administrated group showed a profound expression of apoptotic data as revealed by the flow cytometry method and was further supported by upregulation of Bax protein. Further, the results with the signaling pathway inhibitors, such as, Z-VAD-FMK suggest that the mode of action of purified terpenoid extract in terms of apoptosis on MG-63 cells may
Table 4: Impact of pre-treated MG-63 cells with caspase inhibitor followed by terpenoid extract in terms of MTT assay

\begin{tabular}{ll}
\hline & Viability (\%) \\
\hline Control & 99.69 \\
Terpenoid treated & 38.62 \\
Z-VAD-FMK + terpenoid & 60.75 \\
\hline
\end{tabular}

be via the caspase cascade and the antioxidant enzyme system signaling pathways.

It has been proved that many phytochemicals are able to induce apoptosis on MG-63 human osteosarcoma cells; however, the role of terpenoids from the unexplored plant group mosses on MG-63 cells has not yet elucidated. Terpenoids, the major pungent factor of capsicum, has long been employed in drugs for loss of weight and has been used as an active drug for cancer treatment in terms of inducing apoptosis in diverse malignant cell types under in vitro conditions. In addition, the molecule has been showing to induce apoptosis under in vivo condition as the mode of tumor cell elimination in rat models. These observations made us to trial terpenoids as a plausible antimetastatic drug.

This study was planned to analyze terpenoids triggered apoptosis in MG-63 human osteosarcoma cells and its underlying molecular mode of actions. Using flow cytometry and Western blot analysis, the anticancer effect of terpenoids was demonstrated, which comprises morphological modifications, reduced cell viability, and apoptosis on the MG-63 cells. The overall results revealed that terpenoids are able to block cell viability, their growth and apoptosis.

The aqueous and methanolic extracts of Myristica fragrans seeds showed the presence of alkaloids, saponin, steroids, flavonoids, cyanogenic glycosides, cardiac glycosides, phlobatannins, and phenols. The crude plant extract displayed significant anticancer activity on human osteosarcoma cancer cell lines (MG-63). Significant decreases in cell viability were noticed at concentrations such as $18.75,37.5,75$, and $150 \mu \mathrm{g} / \mathrm{mL}$. The $\mathrm{IC}_{50}$ value was calculated as $95.74 \mu \mathrm{g} / \mathrm{mL} \cdot{ }^{[13]}$ Aziz et al.$^{[14]}$ studied the anticancer activity of curcuminoid analog, namely, (Z)-3-hydroxy-1-(2-hydroxyphenyl)-3-phenylprop-2-en-1one (DK1) and reported that the curcumin analog of DK1 showed effective cytotoxic activity against U-2 OS and MG-63 cells. It displayed morphological changes, and also reduced the cell numbers via the induction of apoptosis. After treatment with curcumin analog of DK1, several apoptotic genes and proteins were up-regulated, such as, caspase 3 , caspase 9 , and BAX, indicating that apoptosis occurred through a mitochondrial-dependent signaling pathway. Jun et al. ${ }^{[15]}$ investigated the anticancer property of curcumin in two human osteosarcoma cell lines, U20S and MG-63. They reported that the proliferation of the osteosarcoma cells was significantly inhibited in a time and concentration-dependent manner when incubated 
with curcumin. After treatment with curcumin, the expression level of apoptosis-related proteins increased and subsequently the level of apoptosis. Gajendiran et al. $^{16}$ reported that the Ocimum basilicum seed extracts possess significant anticancer activity. It showed cytotoxic effect on MG-63 human osteosarcoma cell lines. The cell viability percentage showed significant reduction at the lowest concentration, i.e., $12.5 \mu \mathrm{g} / \mathrm{mL}$. With higher concentration of the extract, there was profound cell death or cell deterioration, like shrunken with membrane blebbing and also signs of detachment fr om the surface of the wells indicating cell death. Scoparone, isolated from Artemisia capillaries, inhibited the proliferation of DU145 cells via cell cycle arrest in the $\mathrm{G}_{1}$ phase. Western blot and quantitative real-time polymerase chain reaction (PCR) analyses revealed that scoparone suppressed the transcription of STAT3 target genes such as cyclin D1, c-Myc, survivin, Bcl-2, and Socs3. The transcriptional activity of STAT3C was also inhibited by scoparone (Kim et al., 2013). ${ }^{17}$

Thus, the present study described the effect of purified terpenoids on MG-63 cells and also elucidated the molecular modes that facilitated in the indution of apoptosis. In combination, the data revealed that terpenoids induced apoptosis on the MG-63 cells was mainly through the caspase cascade and antioxidant enzyme regulatory signaling pathways. Further, in vitro and in vivo animal studies are warranted to ascertain the role of terpenoids before trailing to human beings.

\section{ACKNOWLEDGEMENT}

This study was supported by the Junior Research Fellowship from the CSIR-UGC, New Delhi, India.

\section{REFERENCES}

1. Asakawa Y, Ludwiczuk A, Hashimoto T. Cytotoxic and antiviral compounds from bryophytes and inedible fungi. J. Pre-Clin. Clin. Res. 2013;7:73-85.

2. Saxena DK, Harinder. Uses of bryophytes. Resonance. 2004;56-65.

3. Indumathi C, Durgadevi G, Nithyavani S, Gayathri PK. Estimation of terpenoid content and its antimicrobial property in Enicostemma litorrale. Int. J. ChemTech Res. 2014;6:4264-4267.

4. Kumar RR, Karunagaran SD. Ectopic expression of Bcl-XL or Ku70 protects human colon cancer cells (SW480) against curcumin induced apoptosis while their down regulation potentialities. Carcinogenesis. 2004;25:1867-1877.

5. Lu Z, Jiang G, Blume-Jensen P, Hunter T. Epidermal growth factor-induced tumor cell invasion and metastasis initiated by dephosphorylation and downregulation of focal adhesion kinase. Mol Cell Biol. 2001;21:4016-4031.

6. Ding GF, Huang FF, Yang ZS, Di YU, Yang, YF. Anticancer activity of an oligopeptide isolated from hydrolysates of sepia ink. Chin. J. Nat. Med. 2011;9:151-155.

7. Jacob B, Natarajan S, Pattiyappan S, Sivarman RK, Suresh SM. Study on anticarcinogenic and apotoptic properties of methanolic stem extract of Cardiospremum halicacabum in MCF 7 cell line. J. Sci. Innovative Res. 2015;4:43-48.

8. Peng Q, Deng Z, Pan H, Gu L, Liu O, Tang Z. Mitogen-activated protein kinase signaling pathway in oral cancer (Review). Oncology Lett. 2018;15:1379-1388.

9. MacKenzie SH, Clark AC. Targeting Cell Death in Tumors by Activating Caspases. Curr. Cancer Drug Targets. 2008;8: 98-109.

10. Sypniewski D, Szkaradek N, Loch T, Waszkielewicz AM, Krzyzak AG, Matczynska D, et al. Contribution of reactive oxygen species to the anticancer activity of aminoalkanol derivatives of xanthone. Invest New Drug. 2018;36:355-369.

11. Anita, Sharma HP, Jain P, Amit P. Apoptosis (programmed cell death)-a review. World J. Pharma. Res. 2014;3:1854-1872.

12. Damarla M, Parniani AR, Johnston L, Maredia H, Serebreni L, Hamdan 0, et al. Mitogen-activated protein kinase-activated protein kinase 2 mediates apoptosis during lung vascular permeability by regulating movement of cleaved caspase 3. Am. J. Respir. Cell Mol. Biol. 2014;50:932-941.

13. Sudevan S, Das D, Ramasamy V. Tumorolytic activity of Myristica fragrans metabolic compounds $M$. fragrans in cancer studies. Int. J. Appl. Pure Sci. Agric. 2017;3:19-28.

14. Aziz MNM, Hussin Y, Rahim NFC, Nordin N, Mohamad NE, Yeap SK, et al. Curcumin analog DK1 induces apoptosis in human osteosarcoma cells in vitro through mitochondria-dependent signaling pathway. Molecules. 2018;23:2-15.

15. Jun W, Peng C, Wen J, Mingzhi G. Experimental study on curcumin inhibiting proliferation and invasion of human osteosarcoma cells. Biomed. Res. 2017;28:4396-4401.

16. Gajendiran A, Thangaraman V, Thangamani S, Ravi D, Abraham J. Antimicrobial, antioxidant and anticancer screening of Ocimum basilicum seeds. Bull. Pharm. Res. 2016;6:114-119.

17. Kim JK, Kim JY, Kim HJ, Park KG, Harris RA. Scoparone exerts antitumor activity against DU145 prostate cancer cells via inhibition of STAT3 activity. PLoS ONE. 2013;8:1-13. 